\title{
On the dynamics of the South China Sea Warm Current
}

\author{
Jiayan Yang, ${ }^{1}$ Dexing $\mathrm{Wu}^{2}$ and Xiaopei $\mathrm{Lin}^{2}$ \\ Received 29 June 2007; revised 2 October 2007; accepted 14 January 2008; published 5 August 2008.
}

[1] The South China Sea Warm Current (SCSWC) flows northeastward over the shelf and continental slope in the northern South China Sea (SCS). This current persists in its northeastward direction in all seasons despite the fact that the annually averaged wind stress is decisively southwestward against it. Two major mechanisms have been proposed in previous studies, one attributing it directly to the wind stress forcing within the SCS and the other to the Kuroshio intrusion through the Luzon Strait. In this study we use a simple model to demonstrate that neither of them is the leading forcing mechanism. Instead, the SCSWC is a source- and sink-driven flow induced by the Taiwan Strait Current (TSC), a year-round northward flow through the Taiwan Strait. The two previously suggested mechanisms are important but secondary. The model simulations show that the local wind stress alone would force a current in the opposite direction to the SCSWC. Blocking the Kuroshio intrusion through the Luzon Strait, on the other hand, only weakens the SCSWC. The SCSWC vanishes when the Taiwan Strait is closed in the model.

Citation: Yang, J., D. Wu, and X. Lin (2008), On the dynamics of the South China Sea Warm Current, J. Geophys. Res., 113, C08003, doi:10.1029/2007JC004427.

\section{Introduction}

[2] The South China Sea (SCS) is a large, semienclosed marginal sea in the Northwestern Pacific Ocean. The Luzon Strait (Figure 1) is the widest (about $340 \mathrm{~km}$ ) and deepest (about $2500 \mathrm{~m}$ ) connecting channel through which there is a net transport of the western Pacific Ocean water into the SCS [Qu et al., 2000]. The transport through the Luzon Strait is balanced by outflows to the East China Sea (ECS) through the Taiwan Strait, to the Sulu Sea through the Mindoro Strait and to the Indonesian Seas through the Karimata Strait. In addition to these lateral exchanges, the monsoonal wind stress also plays a prominent role in forcing the seasonally varying circulation in the SCS [e.g., Metzger and Hurlburt, 1996].

[3] The South China Sea Warm Current (SCSWC), named originally by Guan and Chen [1964], flows northeastward toward Taiwan Strait along shelf break and inner continental slope depending on the seasons [Zhong, 1990]. The origin of this perennial northward current can be traced to the vicinity of Hainan Island, a distance of 600-700 km from the southern tip of the Taiwan Strait [Guan, 1985]. In the winter season, the SCSWC is sandwiched between two currents, the southward Guandong Coast Current (GCC), which is the SCS segment of a larger China Coast Current (CCC), and the southward current along the continental slope that is related to the basin-wind cyclonic gyre in the

\footnotetext{
${ }^{1}$ Department of Physical Oceanography, Woods Hole Oceanographic Institution, Woods Hole, Massachusetts, USA.

${ }^{2}$ Physical Oceanography Laboratory, Ocean University of China, Qingdao, China.

Copyright 2008 by the American Geophysical Union. 0148-0227/08/2007JC004427\$09.00
}

SCS [Guan, 1993]. The SCSWC feeds the flow through the Taiwan Strait and thus affects directly the physical and biogeochemical properties in the ECS. The maximum surface speed of the SCSWC was observed to be as high as $30 \mathrm{~cm} / \mathrm{s}$ [Guan, 1978]. The surface wind in the region is dominated by the Asian Monsoon with northeasterly in the winter and southwesterly in the summer. The annually averaged wind stress (Figure 2), however, is decisively southwestward against the SCSWC which persist its northeastward direction in all seasons. Therefore, few have suggested the direct along-shore wind stress alone as the forcing mechanism of the SCSWC. Guan [1986] proposed that the SCSWC is a part of the broader Winter Counterwind Currents (WCWC) off the southeastern coast of China. This was supported by Fang et al. [1991], who further suggested its linkage to the Taiwan-Tsusgima-Tsugaru Warm Current system. Zhong [1990] proposed that the SCSWC is connected dynamically with the South China Sea Branch Current of Kuroshio (SCSBK) which is fed by the Luzon Strait intrusion and flows southward along the continental slope.

[4] As pointed out by Hsueh and Zhong [2004], there had been not yet a commonly accepted explanation for the dynamics that drives the SCSWC even though the current was detected forty years ago. Some numerical studies [e.g., Zeng et al., 1989; Li et al., 1993] hypothesized that alongshore pressure gradient, induced by the water being piled up to the east of Hainan Island, forces the northward flow. Chao et al. [1995] suggested that the return flow of water being piled up in the south near Hainan Island, triggered by a relaxation of the northeasterly monsoon, may give rise to a northward SCSWC. Hsueh and Zhong [2004] disputed these mechanisms, and proposed that the along-shore pressure gradient, resulted from a collision between the 

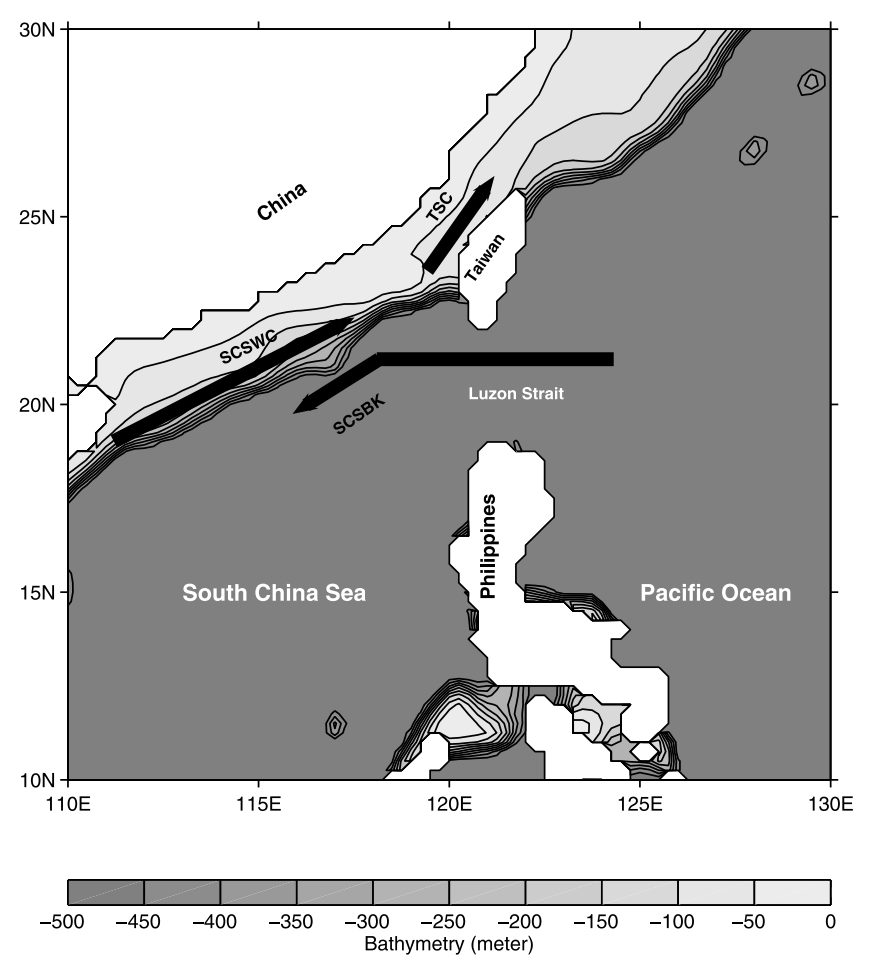

Figure 1. The schematic of the South China Sea Warm Current (SCSWC), the Taiwan Strait Current (TSC), and the South China Sea Branch Current of Kuroshio (SCSBK).

Kuroshio intrusion through the Luzon Strait and the continental shelf, forces a northward flow.

[5] In this paper, we use a barotropic ocean model with a realistic bathymetry and observed wind stress to demonstrate that the SCSWC is forced by the Taiwan Strait Current (TSC) in the form of a source- and sink-driven flow. The Kuroshio intrusion through Luzon Strait, while affects the SCSWC transport, plays an important but secondary role. The robust SCSWC simulated in a model with a steady wind stress suggests that the seasonal relaxation of the northeasterly monsoon is not required in the formation of SCSWC. A suite of experiments will be used to elucidate this mechanism. The description of the model, its forcing fields and the results will be presented in section 2. A brief summary will be given in section 3 .

\section{Model Description}

[6] A one-layer oceanic barotropic ocean circulation model is used in this study. The flow and sea surface height (SSH) in the model are governed by the following equations:

$$
\begin{aligned}
& \frac{\partial u}{\partial t}+u \frac{\partial u}{\partial x}+v \frac{\partial u}{\partial y}-f v=-g \frac{\partial \eta}{\partial x}+\frac{\left(\tau_{S}^{x}-\tau_{B}^{x}\right)}{h} \\
& \frac{\partial v}{\partial t}+u \frac{\partial v}{\partial x}+v \frac{\partial v}{\partial y}+f u=-g \frac{\partial \eta}{\partial y}+\frac{\left(\tau_{S}^{y}-\tau_{B}^{y}\right)}{h} \\
& \frac{\partial \eta}{\partial t}+\frac{\partial(u h)}{\partial x}+\frac{\partial(v h)}{\partial y}=0,
\end{aligned}
$$

where $\eta$ is the SSH, $\rho$ is the density, and $\vec{\tau}_{B}$ is the bottom drag, and $\vec{\tau}_{S}$ is the surface wind stress. The bottom drag is calculated by the following formula:

$$
\overrightarrow{\tau_{B}}=\lambda \vec{u},
$$

where $\lambda=-0.0005 \mathrm{~ms}^{-1}$ is the drag coefficient [Chapman, 1987]. The model resolution is $1 / 8$ degree in space and $20 \mathrm{~s}$ in time. The model covers the whole Pacific Ocean basin zonally and from $5 \mathrm{~S}$ to $45 \mathrm{~N}$ meridionally. The radiation boundary condition is used along $5 \mathrm{~S}$ and $45 \mathrm{~N}$. The 4-year (2000-2003) averaged wind stress derived from observations made by NASA satellite scatterometers (htpp $\backslash:$ www.ssmi. com) is used here (Figure 2). The wind stress data have a resolution of $1 / 4$ degree in both longitude and latitude and thus linearly interpolated into the $1 / 8$ degree model grids. This is a very similar model used by Yang [2007] in his investigation of flow through Taiwan Strait. The ETOPO5 bathymetry data [Edwards, 1989] is used in the model. We are aware that the circulation in the region can be very sensitive to small errors of bathymetry data [Metzger and Hurlburt, 2001].

\section{Results and Discussions}

\subsection{Flow Through Taiwan Strait}

[7] Our hypothesis is that the perennial northward flow through the Taiwan Strait induces the downstream response over the northern shelf in the SCS that gives rise to the SCSWC. The downstream direction is defined here in terms of energy propagation by topographic Rossby waves instead of by the flow direction. In the northern hemisphere, a long Rossby wave propagates in the direction with high potential vorticity (PV) on the right hand side. So along the shelf and slope in the ECS and SCS, the energy propagates southwestward along the bathymetry. So in terms of energy propagation, the SCSWC is located in the downstream of the TSC. Before testing this hypothesis we will review briefly the forcing mechanism of the transport through the Taiwan Strait so that we can understand better the ultimate forcing mechanism of the SCSWC.

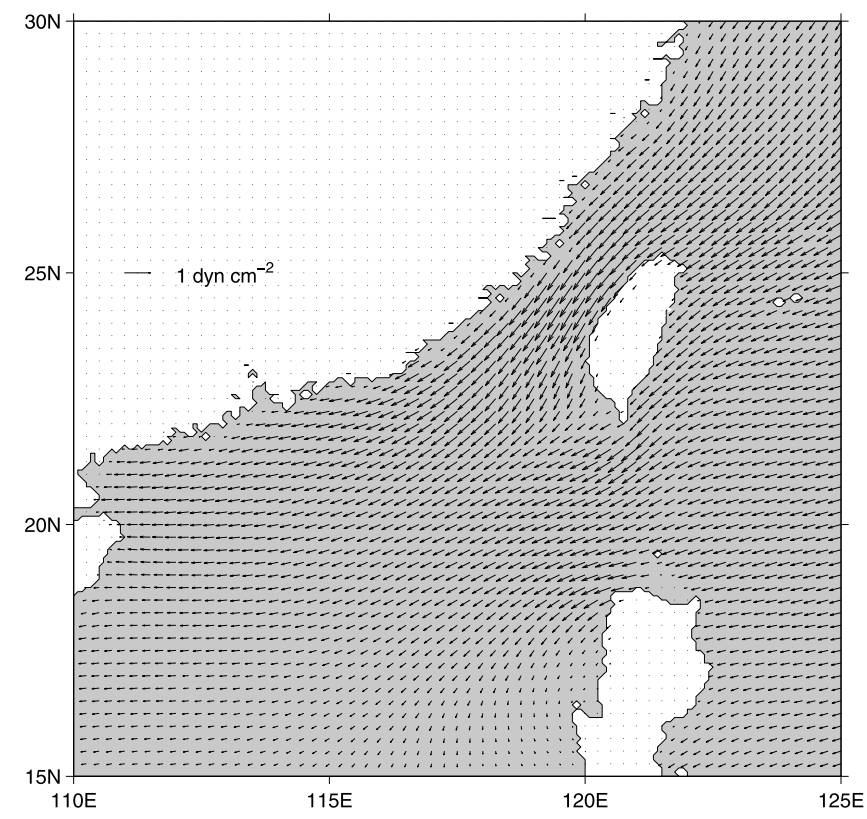

Figure 2. The annually averaged wind stress from the 4-year satellite scatterometer data. The wind stress is southwestward along the northern SCS shelf against the SCSWC direction shown in Figure 1. 
Model Bathymetry and Velocity from the Standard Run

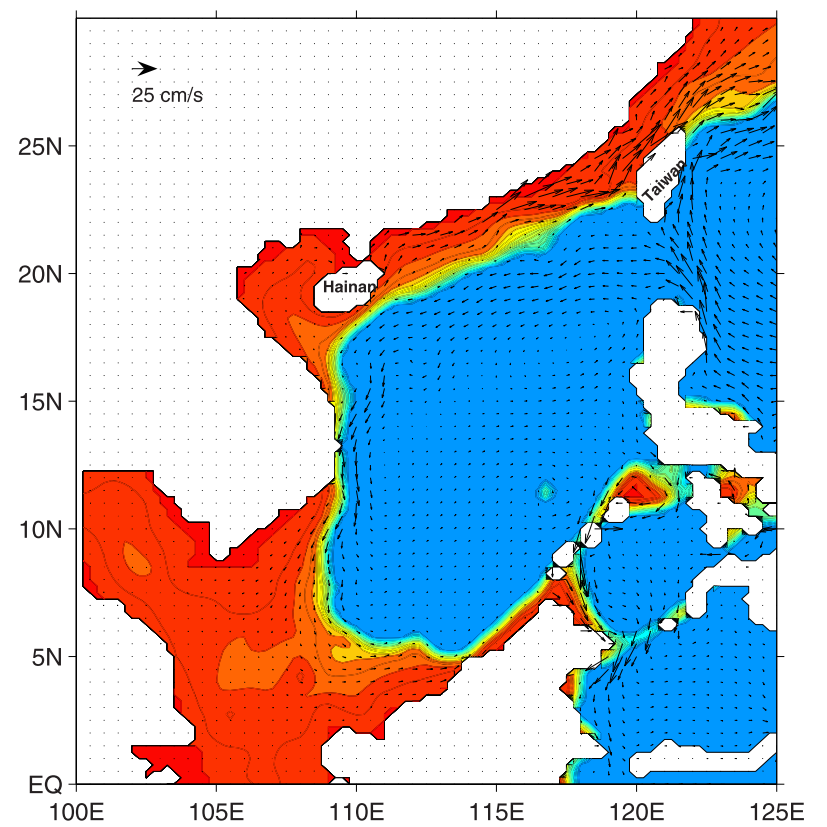

$<$\begin{tabular}{llllllllll}
\hline 00 & -450 & -400 & -350 & -300 & -250 & -200 & -150 & -100 & -50
\end{tabular}

Figure 3. The model bathymetry and velocity from the standard run in the South China Sea region (the actual model domain is from $5 \mathrm{~S}$ to $45 \mathrm{~N}$ and across the Pacific Basin). Note that the model is able to simulate both SCSWC and SCSBK well.

[8] Yang [2007] used the same model described in section 2 to investigate why the flow through the Taiwan Strait is northward perennially despite that the annually averaged wind is decisively southward (Figure 2). The northward flow through the Taiwan Strait is forced mainly by the pressure difference between the southern and northern strait, as suggested in some previous studies. Yang [2007] argued that this pressure difference is induced by the Kuroshio interaction with the Island of Taiwan. The flow along the east coast of Taiwan, i.e., the Kuroshio Current, is governed by the western boundary layer dynamics in which the leading dynamic balance for the alongshore flow is between the friction and along-shore pressure gradient with local wind stress altering this balance. The Coriolis term vanishes owing to the no-normal-flow condition. Integrating this equation from the southern to the northern tip of Taiwan along the east coast yields a considerable pressure difference that must exist to counter the integration of friction and wind stress. This pressure difference, however, is felt on the other side of the Island and thus forces a northward flow parallel to the Kuroshio. The local wind stress forcing acts against this northward flow. The direct interaction between Taiwan and Kuroshio is the main mechanism for the northward transport through Taiwan Strait. The Tsushima Warm Current, which drains water from the East China Sea to the Japan/East Sea, forces flows along isobaths over the East China and Yellow Seas, and makes an important secondary contribution for the transport along the west coast of Taiwan (J. Yang et al., Kuroshio interaction with the East Asian Marginal Seas, submitted to Journal of Physical Oceanography, 2008).

\subsection{Forcing of the South China Sea Warm Current}

[9] In the first experiment we use the whole model domain from $5 \mathrm{~S}$ to $45 \mathrm{~N}$ meridionally and across the whole Pacific Basin zonally with unaltered bathymetry except that we set the minimum water depth to be $10 \mathrm{~m}$. The annually averaged wind stress is applied over the whole model domain. This experiment is hereafter referred as the standard run and used to compare with results from additional sensitivity experiments in which the model setup or the forcing is altered. The model was integrated from a state of rest and reached a steady state after 30 years. The result to be shown is taken at the end of this 30 -year integration.

[10] The model bathymetry and velocity field over the SCS region from the standard run are shown in Figure 3. The model appears to simulate the major currents reasonably well. A robust SCSWC is shown to flow along the northern shelf from the Coast of Hainan Island to the Taiwan Strait, just as schematized in Figure 1. Offshore of SCSWC is a flow in the opposite direction that is fed by the Kuroshio intrusion through the Luzon Strait. This current was called the South China Sea Branch of Kuroshio (SCSBK) [Hsueh and Zhong, 2004] and is a part of the basin-wide cyclonic gyre over the whole South China Sea. The model-simulated transport through the Taiwan Strait is about $1.5 \mathrm{~Sv}$, a bit smaller than the estimated value of $2 \mathrm{~Sv}$ from observations [Fang et al., 1991]. The transport through Luzon Strait is about $5.3 \mathrm{~Sv}$, considerably higher than $3 \pm 1 \mathrm{~Sv}$ estimated by Yaremchuk and $Q u$ [2004]. The transport through the Mindoro Strait (about $3 \mathrm{~Sv}$ ) is by far the largest among the southern straits. The profile of the along-shore velocity across the shelf break at $22 \mathrm{~N}$ is shown in Figure 4 (black line for the standard run). The maximum velocity in the along-shore direction reaches $15 \mathrm{~cm} / \mathrm{s}$ and the SCSWC transport at $22 \mathrm{~N}$ from this annually mean simulation is about 1.7 Sv. Guan [1978] suggested that

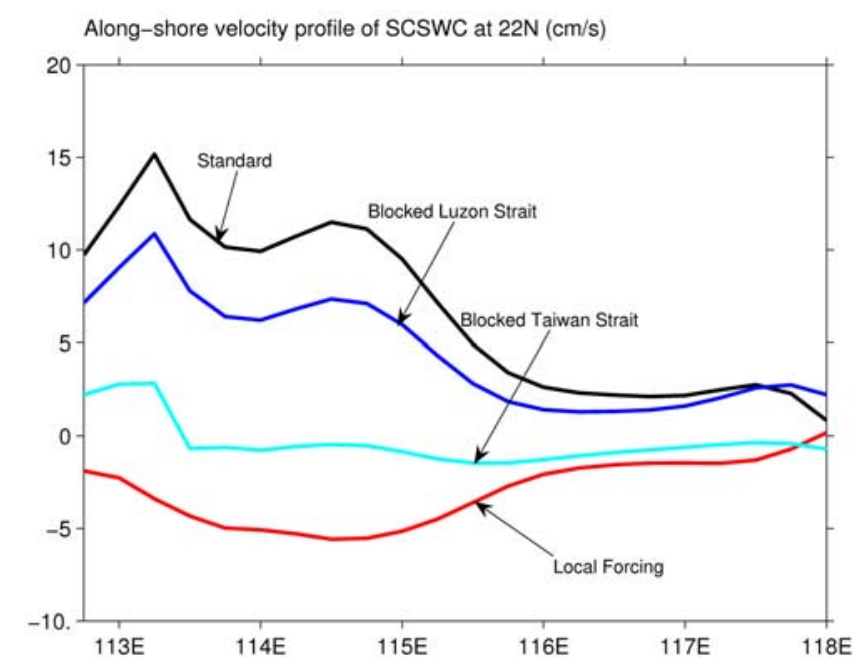

Figure 4. The along-shore velocity profile at $22 \mathrm{~N}$ from the standard run (black), the blocked Luzon Strait run (blue), the local forcing run (red) and the blocked Taiwan Strait run (cyan). 

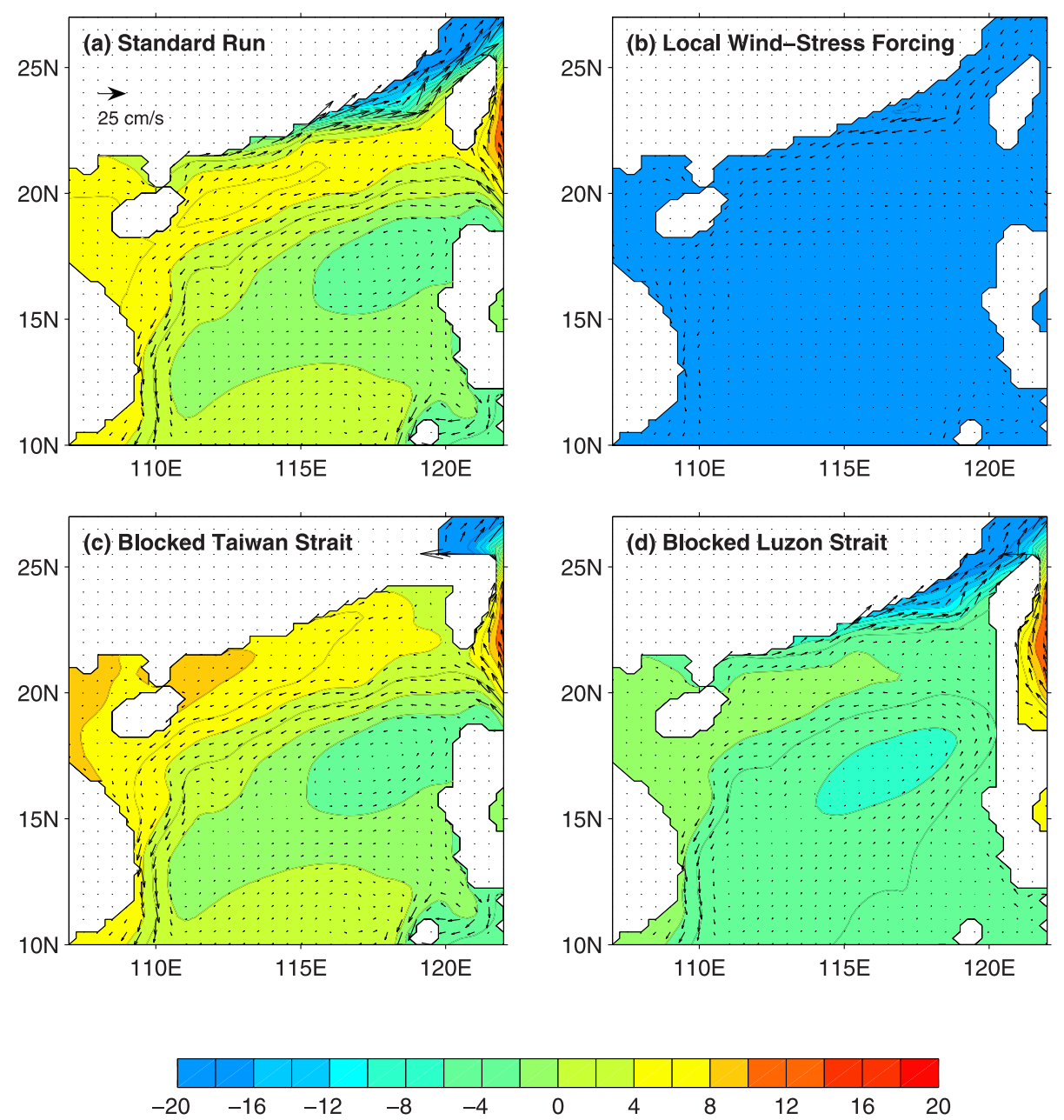

Figure 5. The sea surface height $(\mathrm{cm})$ and the velocity field from (a) the standard run, (b) the local forcing run, (c) the blocked Taiwan Strait run, and (d) the blocked Luzon Strait run.

the surface velocity can be as high as $30 \mathrm{~cm} / \mathrm{s}$. As noted by many previous studies [e.g., Chao et al., 1995], the SCSWC varies seasonally owing to the local monsoonal forcing. The northward flow is high in the summer when the wind blows in the same direction as the SCSWC, and is retarded in the winter when the wind is directly against the current. So the annually averaged flow in the model is expected to be weaker than the summer velocity. Observations also showed that SCSWC's axis varies seasonally [Zhong, 1990; Guan and Fang, 2006]. The axis is located roughly along the $100 \mathrm{~m}$ isobath in summer but is pushed further offshore to $500 \mathrm{~m}$ isobath in winter. It is not clear whether the presence of the China Coastal Current in winter over the shelf may have contributed to this offshore migration. Our model result (Figure 3) seems to resemble the summer pattern that includes the onshore location of the SCSWC and the absence of the China Coast Current. This is interesting since the annually averaged wind is closer to the winter pattern. The flow through the Taiwan Strait is northward in summer. In winter, the current is northward along the eastern side of the strait while southward along the China's coast (the cross-strait averaged flow is northward). The annually averaged flow resembles that of the summer in the Taiwan Strait. Yang [2007] argued that this is due to the interaction between the Crosio Current and the Taiwan Island. Since the SCSWC is driven by the flow through the Taiwan Strait, it is not surprised to see that it resembles the summer pattern.

[11] Next, we will investigate the role of the local wind stress forcing. We design an experiment in which a much smaller model domain, between the 100E and 130E, is used. An open boundary condition is placed along $130 \mathrm{E}$ to allow signals to propagate outward from the model domain. The wind stress is turned on inside the smaller model domain. In this experiment the western boundary current of the subtropical gyre, i.e., the Kuroshio Current, is expected to be very weak without the forcing of wind stress curl in the vast interior to the east of $130 \mathrm{E}$. We refer this experiment as the local forcing run. The annually averaged wind stress in the region is strongly southwestward. It drives a southward flow over the shelf edge from the Taiwan Strait to the Coast of Hainan (Figure 5b) which is opposite to the observed SCSWC direction (Figure 1). The red line in Figure 4 is the profile of the along-shore velocity component at $22 \mathrm{~N}$. The southwest current over the shelf is rather weak, with a maximum velocity of about $5 \mathrm{~cm} / \mathrm{s}$. Another striking contrast between this local forcing run and the standard run, shown in Figure 3, is the absence of the Kuroshio and thus 
the absence of intrusion through the Luzon Strait. The comparison between Figure 3 and Figure 5 suggests that the local wind stress is very unlikely to be the primary forcing mechanism for the SCSWC, at least in terms of the barotropic dynamics. It is interesting to note that the southward flow in this local forcing case resembles the China Coast Current which is robust in the winter when the northeasterly monsoon is strong.

[12] Another previously suggested mechanism attributes the SCSWC to the intrusion of Kuroshio through the Luzon Strait. Hsueh and Zhong [2004] found that the alongshore pressure gradient forces the SCSWC in their numerical model. In our standard run, there is indeed a pressure gradient along the shelf that supports the northward SCSWC (Figure 5a), which is consistent qualitatively with that from Hsueh and Zhong [2004]. The question that we want to address here is what sets this pressure gradient. First we would like to examine whether the Kuroshio intrusion through the Luzon Strait is a determining factor. To do that, we designed an experiment in which the Luzon Strait is completely blocked while everything else in the model remains identical to the standard run. This experiment will be referred to the blocked Luzon Strait run. The circulation inside the SCS changes considerably (Figure 5d) owing to the absence of the Pacific Water intrusion through the Luzon Strait. But the northeastward flow through the Taiwan Strait remains robust and so does the SCSWC along the northern SCS shelf. The profile of the alongshore velocity component at $22 \mathrm{~N}$, indicated by the blue line in Figure 4, is similar to that of the standard run except the magnitude becomes smaller. The total SCSWC transport at this latitude drops from 1.7 Sv to about 1.1 Sv. Blocking the Luzon Strait also changes the SCS exchanges with the western Pacific Ocean. The mass balance in the standard run is between the inflow through the Luzon Strait and outflows through the Taiwan and Mindoro Straits (transports through other southern passages, such as Karimata Strait, are weaker in the model). When the Luzon Strait is closed, the flow through Mindoro Strait reverses and the inflow there balances the outflow through the Taiwan Strait. The result from this experiment appears to support our hypothesis that the SCSWC is forced by the northward transport through the Taiwan Strait. As discussed by J. Yang et al. (submitted manuscript, 2008), about $1 / 3$ of the annualmean transport through the Taiwan Strait (1.5 Sv in the standard run) is remotely forced by the Tsushima Warm Current which sucks water from the ECS into the Japan/East Sea and thus induces a northward flow over a broad region in the ECS. The Kuroshio interaction with the Taiwan Island contributes $2 / 3$ to the transport. The $1.1 \mathrm{~Sv}$ of the SCSWC transport at $22 \mathrm{~N}$ in this closed blocked Luzon Strait run is still much greater than the $0.5 \mathrm{~Sv}$ transport through the Taiwan Strait that is attributed to the Tsushima Warm Current by Yang et al. (submitted manuscript, 2008). The Kuroshio forcing in this blocked Luzon Strait run results in an inflow through the Mindoro Strait and an outflow through the Taiwan Strait, likely with the same mechanism that forces the flow through Taiwan Strait in the standard run, and contributes to the northward transport at $22 \mathrm{~N}$. We must point out here that the role of another western boundary current, the Mindanao Current, must be considered in the blocked Luzon Strait run. The net pressure difference between the northern tip of the Taiwan Strait and the Mindoro Strait is determined by the accumulated friction exerted by both the Kuroshio and the Mindanao Currents. These two WBCs bifurcate at about $14.3 \mathrm{~N}$ with roughly same transport [Yaremchuk and Qu, 2004]. The length of the western boundary from $14.3 \mathrm{~N}$ to the northern tip of Taiwan is longer that that from $14.3 \mathrm{~N}$ to the Mindoro Strait. The surface pressure would be higher at the Mindoro than at the Taiwan Strait if other factors, such as bathymetric variations, are not considered. This would force an inflow through the Mindoro Strait into the SCS and contribute to a northward SCSWC.

[13] If the SCSWC is indeed forced by the flow through Taiwan Strait, one would wonder what would occur if the flow through the Taiwan Strait is absent. To do so we design the next experiment, referred to hereafter as the blocked Taiwan Strait run, in which the Taiwan Strait is closed. Everything else in the model remains the same as the standard run. Figure 5c shows that the northeastward SCSWC vanishes completely. In fact the flow over a large portion of the shelf between Taiwan and Hainan reverses to the southwestward direction, parallel to the offshore flow associated with the Luzon Strait intrusion. The alongshore velocity profile at $22 \mathrm{~N}$, shown by the cyan line in Figure 4, clearly demonstrate that the along-shelf flow in the northern SCS is very weak without the flow through the Taiwan Strait.

[14] To further examine our hypothesis, we designed another experiment in which the surface forcing is turned off completely over the whole model domain. Instead, the model is forced by a specified velocity profile across Taiwan Strait. The velocity profile used here is taken from the standard run. The process of doing this is to run the model over the whole domain, and the velocity field across Taiwan Strait along $25 \mathrm{~N}$ is reset to be the one from the standard run after each time step in the model integration. Figure 6 shows the velocity field on top of the background bathymetry. A robust flow over the shelf is established and is very similar to that from the standard run (Figure 3). This further supports our hypothesis that the SCSWC is induced by the Taiwan Strait Current.

\section{Discussion and Summary}

[15] In this study we test a hypothesis that the SCSWC is forced by the northward transport through the Taiwan Strait which itself is forced primarily by the Kuroshio Current [Yang, 2007; Yang et al., submitted manuscript, 2008]. The model, when using realistic bathymetry and observed wind stress, simulates a SCSWC pattern consistent with an observed one. When the northward flow through the Taiwan Strait is absent, either owing to the absence of the Kuroshio or a change of model geometry, the SCSWC vanishes. In addition, blocking the Luzon Strait affects only quantitatively the model results. All our sensitivity tests support strongly that the SCSWC is an along-isobaths flow induced by the Taiwan Strait Current in the form of a source- and sink-driven current.

[16] The model used in this study is a simple one-layer barotropic model and is forced by the annually averaged wind stress. One would wonder if such a simple model is adequate for addressing the forcing mechanism of a highly seasonal current in a dominantly monsoonal forcing area. 

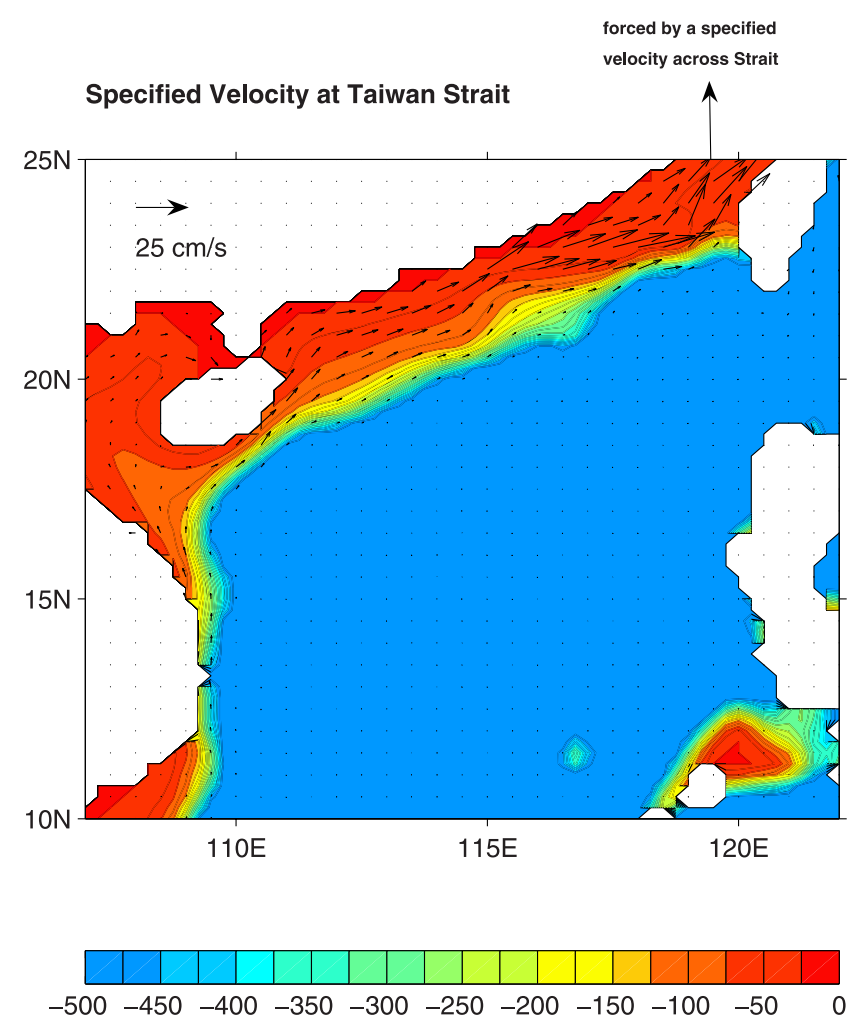

Figure 6. The velocity field and bathymetry for the source- and sink-driven flow induced by specifying the velocity profile across Taiwan Strait.

D. Wu et al. (Open-ocean forcing in shallow coastal seas: A mechanism for circulations in the East China and Yellow seas, manuscript in preparation, 2008) used a high-resolution three-dimensional Princeton Ocean model (1/8 degree laterally and 14 layers vertically) and used seasonally varying forcing fields of wind stress and buoyancy fluxes. They repeated all experiments reported by Yang et al. (submitted manuscript, 2008), including 3 experiments shown in this paper, i.e., the standard run, the blocked Luzon Strait run and the local forcing run. The annually mean results from their three-dimensional model are virtually the same as in the one-layer model. For instance, blocking the Luzon Strait in their 3-D model does not remove the SCSWC, and the local forcing alone would result in a southwestward flow over the shelf and in the inner continental slope. While Wu et al.'s focused on the modulation mechanisms of the seasonal variability of major currents in the East Asian Marginal Seas, they nevertheless concluded that the simple one-layer barotropic model is adequate for addressing the depth-averaged and annually mean flow field in the region.

[17] Finally, we would like to remark that our hypothesis is consistent with previous studies [e.g., Fang et al., 1991] in the sense that SCSWC is dynamically connected with the Taiwan Strait Current, the Taiwan Warm Current, the Tsushima Warm Current and outflow from the Japan/East Sea through the Tsugaru Strait, and all these currents should be considered as local manifestation of a larger counterwind current system. But we differ from those previous studies in terms of cause-effect relationship among those currents. We considered the SCSWC as a downstream current that is influenced by other currents further north. This definition of 'downstream' is dynamically based on the direction of energy propagation. Here we have shown that specifying a velocity profile across the Taiwan Strait would induce flow in the SCS instead of in the ECS. So the SCS is dynamically a downstream region to the forcing in the Taiwan Strait, which itself is a downstream region for variability in the ESC and the Tsushima Strait. This contrasts with some other studies that regarded the ECS and JES as downstream regions to the SCS [e.g., Fang et al., 1991]. Their definition was based on the flow direction since most of the counter-wind currents in the region are northward. It has often postulated that the elevated sea surface height $(\mathrm{SSH})$ in the SCS plays a role to push the counter-wind currents all the way from the SCS through the ECS to the JES [Guan and Fang, 2006; Fang et al., 1991]. Since the topographic Rossby waves travel southward along the bathymetry in this region and shallow-water gravity waves also travel southward along the sea-land boundary, external forcing or oceanic variability in the SCS could not affect directly the ECS and JES through local pathways. The eventual responses in the ECS and JES would have to be through the basin-wide adjustments involved with planetary Rossby waves and equatorial Kelvin waves [Anderson and Gill, 1975]. On the other hand, the SCSWC is sensitive to changes or forcing in the Taiwan Strait as our last experiment shows, and the flow through the Taiwan Strait and over the ECS are responsive to forcing in the JES as demonstrated by Yang et al. (submitted manuscript, 2008) We feel that this is not merely a trivial definition difference but a conceptual one which may have some important implications for developing a predictive skill for variability in the broader East Asian Marginal Seas.

[18] Finally, we would like to point out that the mechanism for the seasonal variability of the SCSWC remains to be investigated. A more complete understanding must include the seasonal modulation of the SCSWC, especially regarding the seasonal offshore migration of the warm current. The seasonal monsoonal forcing would probably become a more dominant player for the seasonal variability. $\mathrm{Wu}$ et al. (manuscript in preparation, 2008) studied another warm current, the Yellow Sea Warm Current, in a 3-D model and reported that the annual-mean transport is forced primarily by the Kuroshio but the seasonal variability is due mainly to the local monsoonal forcing. The presence of the China Coast Current in winter is essential for the seasonal changes of major currents in the region. The winter offshore migration of the SCSWC is accompanied by the development of a robust southward coastal current as shown by observations [Zhong, 1990]. But is not clear how these two currents affect each other.

[19] Acknowledgments. This study has been supported by the U.S. National Science Foundation (OCE-0351055), China's International Science and Technology Cooperation Program (2006DFB21250), and China's National Basic Research Priorities Program (2005CB422302). We thank Shang-Ping Xie and one anonymous reviewer for their very constructive and helpful comments and suggestions.

\section{References}

Anderson, D. L. T., and A. E. Gill (1975), Spin-up of a stratified ocean with application to upwelling, Deep Sea Res., 22, 583-596. 
Chao, S.-Y., P.-T. Shaw, and J. Wang (1995), Wind relaxation as a possible cause of the South China Sea Warm Current, J. Oceanogr., 51, 111-133, doi:10.1007/BF02235940.

Chapman, D. C. (1987), Application of wind-forced, long, coastal-trapped wave theory along the California coast, J. Geophys. Res., 92, 17981816, doi:10.1029/JC092iC02p01798.

Edwards, M. O. (1989), Global gridded elevation and bathymetry (ETOPO5), report, Natl. Geophys. Data Cent., NOAA, Boulder, Colo.

Fang, G., B. Zhao, and Y. Zhu (1991), Water volume transport through the Taiwan Strait and the continental shelf of the East China Sea measured with current meters, in Oceanography of Asian Marginal Seas, edited by K. Takano, pp. 345-358, Elsevier, Amsterdam.

Guan, B. (1978), New evidences of the South China Sea Warm Current (in Chinese), Ocean Sci., Suppl., 1, 100-103.

Guan, B. (1985), Some features of temporal and spatial distributions of the "counter-wind" current in northern South China Sea in winter (in Chinese with English abstract), Oceanol. Limnol. Sin., 16(6), 429-438.

Guan, B. X. (1986), Evidence for a counter-wind current in the winter off the southeast coast of China, Chin. J. Oceanol. Limnol., 4, 319-332, doi:10.1007/BF02845279.

Guan, B. X. (1993), Winter counter-wind current off the southeastern China coast and a preliminary investigation of its source, in Proceedings of the Symposium on the Physical and Chemical Oceanography of the China Seas, pp. 1-9, China Ocean Press, Beijing.

Guan, B. X., and S. J. Chen (1964), The current systems in the near-sea area of China Seas (in Chinese), report, 88 pp., Natl. Mar. Surv., Beijing.

Guan, B., and G. Fang (2006), Winter counter-wind currents off the southeastern China coast: A review, J. Oceanogr., 62, 1-24, doi:10.1007/ s10872-006-0028-8.

Hsueh, Y., and L. Zhong (2004), A pressure-driven South China Sea Warm Current, J. Geophys. Res., 109, C09014,doi:10.1029/2004JC002374.
Li, R. F., Q. C. Zeng, Z. J. Gan, and W. Z. Wang (1993), Numerical simulation of the South China Sea Warm Current and the Taiwan Strait Flow in winter, Prog. Natl. Sci., 3, 123-129.

Metzger, E. J., and H. E. Hurlburt (1996), Coupled dynamics of the South China Sea, the Sulu Sea, and the Pacific Ocean, J. Geophys. Res., 101, 12,331-12,352, doi:10.1029/95JC03861

Metzger, E. J., and H. E. Hurlburt (2001), The nondeterministic nature of Kuroshio penetration and eddy shedding in the South China Sea, J. Phys. Oceanogr., 31, 1712-1731, doi:10.1175/1520-0485(2001)031<1712: $\mathrm{TNNOKP}>2.0 . \mathrm{CO} ; 2$

Qu, T., H. Mitsudera, and T. Yamagata (2000), Intrusion of the North Pacific waters into the South China Sea, J. Geophys. Res., 105, 64156424, doi:10.1029/1999JC900323.

Yang, J. (2007), An oceanic current against the wind: How does Taiwan Island steer warm water into the East China Sea?, J. Phys. Oceanogr., 37, $2563-2569$

Yaremchuk, M., and T. Qu (2004), Seasonal variability of the large-scale currents near the coast of the Philippines, J. Phys. Oceanogr., 34, 844854, doi:10.1175/1520-0485(2004)034<0844:SVOTLC $>2.0 . C O ; 2$.

Zeng, Q., R. Li, Z. Ji, Z. Gan, and P. Ke (1989), Calculations of the monthly mean circulation in the South China Sea (in Chinese), Sci. Atmos. Sin., $13,127-168$

Zhong, H. L. (1990), Structures of the density circulation (in Chinese), in Report of Decadal Hydrographic Series Survey of the Shelf and Adjacent Waters of the Northern South China Sea, edited by Y. L. Ma et al., pp. 215-241, China Ocean Press, Beijing.

$\mathrm{X}$. Lin and $\mathrm{D}$. Wu, Physical Oceanography Laboratory, Ocean University of China, Qingdao, Postal Code 266003, China.

J. Yang, Department of Physical Oceanography, Woods Hole Oceanographic Institution, Woods Hole, MA 02543, USA. (jyang@whoi.edu) 